\title{
Coexistence of Galanin-like Immunoreactivity with Catecholamines, 5-Hydroxytryptamine, GABA and Neuropeptides in the Rat CNS
}

\author{
T. Melander,* T. Hökfelt, “ Å. Rökaeus, $\dagger$ A. C. Cuello, $\ddagger$ W. H. Oertel, $\S$ A. Verhofstad, $\Uparrow$ and M. \\ Goldstein**

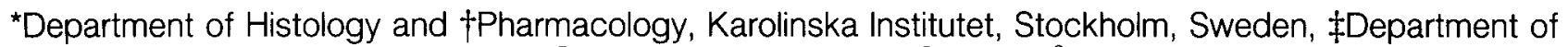 \\ Pharmacology and Therapeutics, McGill University, Montreal, Canada, §Department of Neurology, Technical \\ University of Munich, Munich, Federal Republic of Germany, IDepartment of Pathology, Catholic University, \\ Nijmegen, The Netherlands, and ${ }^{* *}$ Department of Psychiatry, New York University Medical Center, New York, \\ New York
}

The coexistence of galanin (GAL)-like immunoreactivity (LI) with markers for catecholamines, 5-hydroxytryptamine (5-HT), GABA, or some neuropeptides was mapped in the rat CNS by using adjacent sections, as well as by elution-restaining and double-labeling immunocytochemistry. Many instances of coexistence were observed, but there were also numerous GAL-positive cell body populations displaying distributions similar to those of these markers but without apparent coexistence.

In the hypothalamic arcuate nucleus GAL-LI was found in a large proportion of tyrosine hydroxylase (TH)-positive cell bodies (A12 cells), both in the dorsomedial and ventrolateral subdivisions, with a higher number in the latter. GAL-LI coexisted in glutamic acid decarboxylase (GAD)-positive somata in the posterior aspects of the arcuate nucleus and at all rostrocaudal levels in fibers in the external layer of the median eminence. In the anterior hypothalamus, a large population of the cells of the parvocellular and magnocellular paraventricular nuclei contained both GAL-LI and vasopressin-LI. Moreover, somata containing both GAD- and GAL-LI were seen lateral to the mammillary recess in the tuberal and caudal magnocellular nuclei. Some of the neurons of the caudal group were shown to project to the occipital cortex using combined retrograde tracing and immunofluorescence. With regard to mesencephalic and medullary catecholamine neurons, GAL-LI coexisted in a large proportion of the noradrenergic locus coeruleus somata (A6 cell group) and in the A4 group dorsolateral to the fourth ventricle, as well as in the caudal parts of the $A 2$ group in the dorsal vagal complex. However, in more rostral parts of the latter, especially in the medial subdivision of the solitary tract nucleus, a very large population of GAL-IR small cell bodies was seen intermingling with catecholamine neurons, but they did not contain TH-LI. Furthermore, GAL-IR cell bodies coextensive with, but not coexisting in, TH-IR somata were seen in the $C 1$ (epinephrine) horea in the ventrolateral medulla at the level of area postrema and in the most rostral aspects of the $\mathrm{Cl}$ group. Finally, 5-HT-positive cell bodies of the mesencephalic and medullary raphe nuclei and a subpopulation of coarse 5-HT nerve fibers in the hippocampus co-contained GAL-LI.

Received Feb. 3, 1986; revised May 5, 1986; accepted May 6, 1986.

The present study was supported by grants from the Swedish Medical Research Council (04X-2887), Knut and Alice Wallenberg's Stiftelse, Magnus Bergvall's Stiftelse, Karolinska Institutet and Åke Wibergs Foundation, and by an MRC Biotechnology Development Grant (Canada). We thank Ms. Waldtraut Hiort and Ms. Siv Nilsson for expert photographic work and Ms. Elisabet Björklund for skillful secretarial help.

Correspondence should be addressed to Tor Melander, Department of Histology, Karolinska Institute, P.O. Box 60400, 10460 Stockholm, Sweden.

Copyright (C) 1986 Society for Neuroscience $0270-6474 / 86 / 123640-15 \$ 02.00 / 0$
The present results demonstrate that a GAL-like peptide is present in many systems containing other neuroactive compounds, including dopamine, norepinephrine, 5-HT, GABA, and vasopressin. Some hypothalamic neurons containing both $G A L-$ $\mathrm{LI}$ and GABA project to cortical areas. In addition to the presence of GAL-LI in cortically projecting serotonergic, noradrenergic, and GABAergic neurons, cholinergic forebrain neurons projecting to the hippocampal formation also contain GAL-LI, as shown in a previous paper.

The view that ncurons synthesize, store, and perhaps release several neuroactive substances has received increasing support both from morphological studies and, more recently, from functional indications that neuronal signaling can be modulated by co-contained substances (Chan-Palay and Palay, 1983; Cuello, 1982; Hökfelt et al., 1980b, 1984b; Lundberg et al., 1982, for reviews). Brain areas where coexistence is common include, for example, the hypothalamic arcuate nucleus, the magnocellular hypothalamic nuclei, and various catecholamine- and indolamine-containing cell groups in the brain stem.

The neuropeptide galanin (GAL) has been isolated from pig small intestine (Tatemoto et al., 1983). It has been shown to contract intestinal smooth muscle preparations and to cause a mild, prolonged hyperglycemia and inhibition of insulin release (McDonald et al., 1985; Tatemoto et al., 1983). GAL has also been shown to inhibit substance $\mathrm{P}$ - and $\mathrm{ACh}$-induced smooth muscle contraction (Ekblad et al., 1985a). Furthermore, intraventricular injections of this peptide have been shown to cause an elevation of growth hormone levels in plasma (Ottlecz et al., 1985).

Antibodies were raised against GAL and radioimmunoassay and immunohistochemistry have revealed a widespread distribution in both PNS and CNS (Ch'ng et al., 1985; Ekblad et al., 1985b; Melander et al., 1984, 1985a, b, 1986a, b; Rökaeus et al., 1984; Skofitsch and Jacobowitz, 1985). Several previously transmitter-identified cell groups or nuclei were found in these studies to contain coextensive GAL-positive cell body populations. In one case it was established that the GAL-like peptide is present in cholinergic basal forebrain neurons that project to cortical areas (Melander et al., 1985b). In the present paper, further coexistence involving GAL-LI together with other peptides and transmitter-related compounds in neuronal structures in the rat CNS is defined.

\section{Materials and Methods}

\section{Experimental animals}

Twenty-five male Sprague-Dawley rats, 150-180 gm (pathogen-free breed, ALAB, Stockholm, Sweden) were used. Fifteen rats were given 
intraventricular injections of colchicine, $120 \mu \mathrm{g} / \mathrm{rat}$ in $20 \mu \mathrm{l}$ saline (Sigma Chemical Co., St. Louis), while under chloral hydrate anesthesia, 0.5 $\mathrm{gm} / \mathrm{kg}$, i.p.).

Three animals were anesthetized with chloral hydrate (as above) and given 3 stereotaxically placed injections $(200 \mathrm{nl})$ of True blue (Bentvoglio et al., 1980) (Dr. Illing KG, Makromolekulare Chemie, Gross Umstadt, FRG) into the occipital cortex using a $5 \mu \mathrm{l}$ Hamilton syringe (AP 6.0, 6.5, 7.5; ML 2.5, 3.5, 3.5; DV 1.5 at all 3 injection sites; coordinates in relation to bregma). Seven to 9 days later these rats received an intraventricular colchicine injection. All animals were sacrificed $48 \mathrm{hr}$ after colchicine administration. Colchicine arrests axonal transport and thereby increases the levels of peptides, enzymes, and catecholamines in cell bodies (Dahlström, 1968; Hökfelt and Dahlström, 1971; Kreutzberg, 1969). In addition, 3 rats received a 3-mm-deep knife cut lesion of the supracallosal striae, $1 \mathrm{~mm}$ rostral to bregma and extending from the midline $3 \mathrm{~mm}$ laterally. These 3 rats and 4 additional control rats were not treated with colchicine and were used to study nerve fibers.

\section{Preparation of tissues}

The rats were anesthetized with sodium pentobarbital (Nembutal, 30$50 \mathrm{mg} / \mathrm{kg}$, i.p.) and perfused through the ascending aorta with $50 \mathrm{ml}$ PBS, $\mathrm{pH} 6.9$, followed by an ice-cold picric acid-paraformaldehyde mixture (approx. $0.4 \%$ picric acid and $10 \%$ formalin in $0.16 \mathrm{~m}$ sodium phosphate buffer, pH 6.9) for $6 \mathrm{~min}$ (Zamboni and de Martino, 1967). The brain was rapidly dissected out and immersion-fixed for $1.5 \mathrm{hr}$ in the same fixative. The tissue was thereafter rinsed in $10 \%$ sucrose in phosphate buffer containing bacitracin $(0.02 \%)$ and sodium azide $(0.01 \%)$ for at least $48 \mathrm{hr}$ with several changes. Sections were cut at $5-14 \mu \mathrm{m}$ in a cryostat (Leitz, Wetzlar, FRG) and mounted on slides subbed with chrome alum-gelatin.

\section{Immünofluorescence procedure}

The indirect immunofluorescence technique of Coons and collaborators (see Coons, 1958) was used. To establish coexistence 3 procedures were used: (1) staining of adjacent sections, (2) the elution-restaining technique of Tramu et al. (1978), and (3) double-staining (see Nairn, 1969).

The following antisera were used: (1) rabbil GAL antiserum (1:800; Peninsula Laboratories, Merseyside, UK); (2) rabbit GAL antiserum (R28310; raised to porcine GAL conjugated to BSA) (dilution 1:400; Rökaeus et al., 1984); (2) guinea pig antiserum to vasopressin (1:100; GP 24A2) conjugated to thyroglobulin (Elde, 1974); (3) rabbit antiserum to tyrosine hydroxylase (TH) purified from rat pheochromocytoma (1: 400; Markey et al., 1980) and monoclonal mouse antiserum to TH isolated from rat pheochromocytoma (1:30; Semenenko et al., 1986); (4) sheep antiserum to glutamic acid decarboxylase (GAD; S3; 1:1000; Oertel et al., 1981); (5) rabbit and guinea pig antiserum to 5-HT conjugated to BSA (Steinbusch et al., 1978; Verhofstad et al., 1983).

With the "adjacent staining" tcchnique, 2 adjacent sections were incubated with different primary antisera. Thus, GAL antiserum was compared with GAD antiserum and with guinea pig 5-HT antiserum. The antisera were diluted in PBS and contained 0.3\% Triton X-100 (Hartman et al., 1972). The sections were incubated with primary antiserum at $4^{\circ} \mathrm{C}$ in a humid atmosphere for $18-24 \mathrm{hr}$ and were then rinsed in PBS for $20 \mathrm{~min}$, and incubated at $37^{\circ} \mathrm{C}$ for $30 \mathrm{~min}$ with FITC-conjugated swine anti-rabbit immunoglobulin (Dakopatts, Copenhagen) (for GAL), donkey anti-goat immunoglobulin (Nordic, Tilburg. The Netherlands) (GAD) or goat anti-guinea pig (American Qualex, La Mirada, CA). The sections were again rinsed in PBS for 20-30 min, mounted in glycerol: PBS (3:1) containing $0.1 \% p$-phenylenediamine (Johnson and de C. Nogueira Araujo, 1981; Platt and Michael, 1983). The sections were examined in a Zeiss fluorescence microscope equipped with a dark-field oil condenser, as well as KP 500 (for FITC) and BP 546 (for Texas red and rhodamine, see below) excitation filter and the stop filters LP 520 and LP 590 (for FITC and Texas red/rhodamine, respectively). Filters UGI (excitation) and Zeiss 41 (stop) were used for True blue fluorescence. Kodak Tri-X film was used for photography, with exposure times ranging from 10 to $60 \mathrm{sec}$.

The elution-restaining technique was used for analysis of GAL-LI in relation to TH. Sections were incubated with GAL antiserum (as above) and the staining patterns photographed. The antibodies were eluted with acid potassium permanganate $\left(\mathrm{KMnO}_{4}\right)$. Briefly, the sections were immersed in a solution of $3 \% \mathrm{KMnO}_{4}(2.5 \mathrm{ml}), 1 \mathrm{~N} \mathrm{H}_{2} \mathrm{SO}_{4}(2.5 \mathrm{ml})$, and $50 \mathrm{ml}$ distilled water for 30-60 sec. The sections were then incubated with FITC-conjugated swine anti-rabbit immunoglobulins (as above) and examined in the fluorescence microscope. If no green fluorescence was observed, the sections were processed with the rabbit anti- $\mathrm{TH}$ antibody and FITC-conjugated antibodies (as above). The new staining patterns were photographed and compared with the previous ones.

Double-staining experiments were carried out for comparison of the distribution of GAL-LI with TH-, GAD-, or 5-HT-LI. In the first case, rabbit anti-GAI, antibodies (dilution 1:400) were mixed with mouse anti-TH monoclonal antibodies (1:30) and incubated as above. As secondary antibodies, a mixture of Texas red-conjugated donkey antirabbit antibodies (Amersham, Amersham, England) and fluorescein isothiocyanate (FITC)-conjugated goat anti-mouse antibodies (American Qualex) was used. For the second combination, where GAL and GAD were compared, a mixture of rabbit anti-GAL antiserum and sheep antiGAD antiserum was used followed by a mixture of secondary antibodies consisting of Texas red-conjugated donkey anti-rabbit antiserum (Amersham) and FITC-conjugated donkey anti-goat antiserum (Nordic). For the GAL/5-HT double-staining, rabbit anti-GAL and guinea pig anti5-HT primary antibodies were mixed and incubated for $2 \mathrm{hr}$ at room temperature before dilution and incubation with sections (as above). A mixture of FITC-conjugated goat anti-rabbit, preadsorbed to guinea pig immunoglobulins (American Qualex), and rhodamine-conjugated goat anti-guinea pig (American Qualex) antisera was used as secondary antibodies after preincubation as with the primary antisera. Cell profiles, with or without a visible nucleus, were counted.

GAL antiserum preadsorbed with GAL peptide $(10 \mu \mathrm{g} / \mathrm{ml}$ antiserum diluted 1:10) was used as a control.

\section{Results}

Coexistence of GAL-LI with peptides or transmitter synthesizing enzymes was observed in several cases in the hypothalamus and in the lower brain stem. In some instances, the approximate number of immunoreactive cell bodies is given. This always refers to the number of cell profiles per section and side.

\section{Hypothalamus}

GAL-positive somata were present throughout the entire rostrocaudal extent of the arcuate nucleus, with only a few $(\leq 5)$ cells at the retrochiasmatic level extending dorsally into the pcriventricular nuclcus. Ten to 20 cells were seen on each side in the anterior arcuate nucleus proper with single large cells extending laterally. At mid-median eminence levels, large numbers of cells were seen in the ventrolateral part of the nucleus, and some were also seen in its dorsal part (Fig. 1 $A$ ). In addition, a dorsal and a lateral extension of GAL-positive cell bodics appeared and surrounded the ventromedial nucleus. A smaller number of positive cells was seen at the level of the caudal end of the median eminence, while further caudally the number increased again (Fig. $1 B$ ). There, a large number of cell bodies was seen next to the ventricle but also extending in the ventral and dorsal directions at the perimeter of the nucleus. At yet more caudal levels, approximately 20 cells were seen just lateral to the mammillary recess.

A few GAL-IR fibers were seen within the arcuate nucleus, while a very dense network was observed throughout the mediolateral extent of the external layer of the median eminence and a medium dense network in its internal layer (Fig. 1 $A$ ).

The use of the elution-restaining method revealed that a large proportion of the GAL-IR cell bodies of the arcuate nucleus also contained TH-LI (Fig. 1C), i.e., belonged to the A12 THpositive cell group (nomenclature here and in the following according to Dahlström and Fuxe, 1964; Hökfelt et al., 1984c). The highest proportion of coexistence was seen in the ventrolateral part of the arcuate nucleus, where only single somata were found that contained only one of the markers (Fig. 1C). A high degree of coexistence was also seen in the cell bodies extending along the base of the brain and lateral to the ventromedial hypothalamic nucleus. In the dorsal periventricular aspect of the nucleus, the number of GAL-IR cells was comparatively low, and a large proportion of the TH-IR cells in this group seemed to lack the peptide (Fig. 1, $A, C$ ). 

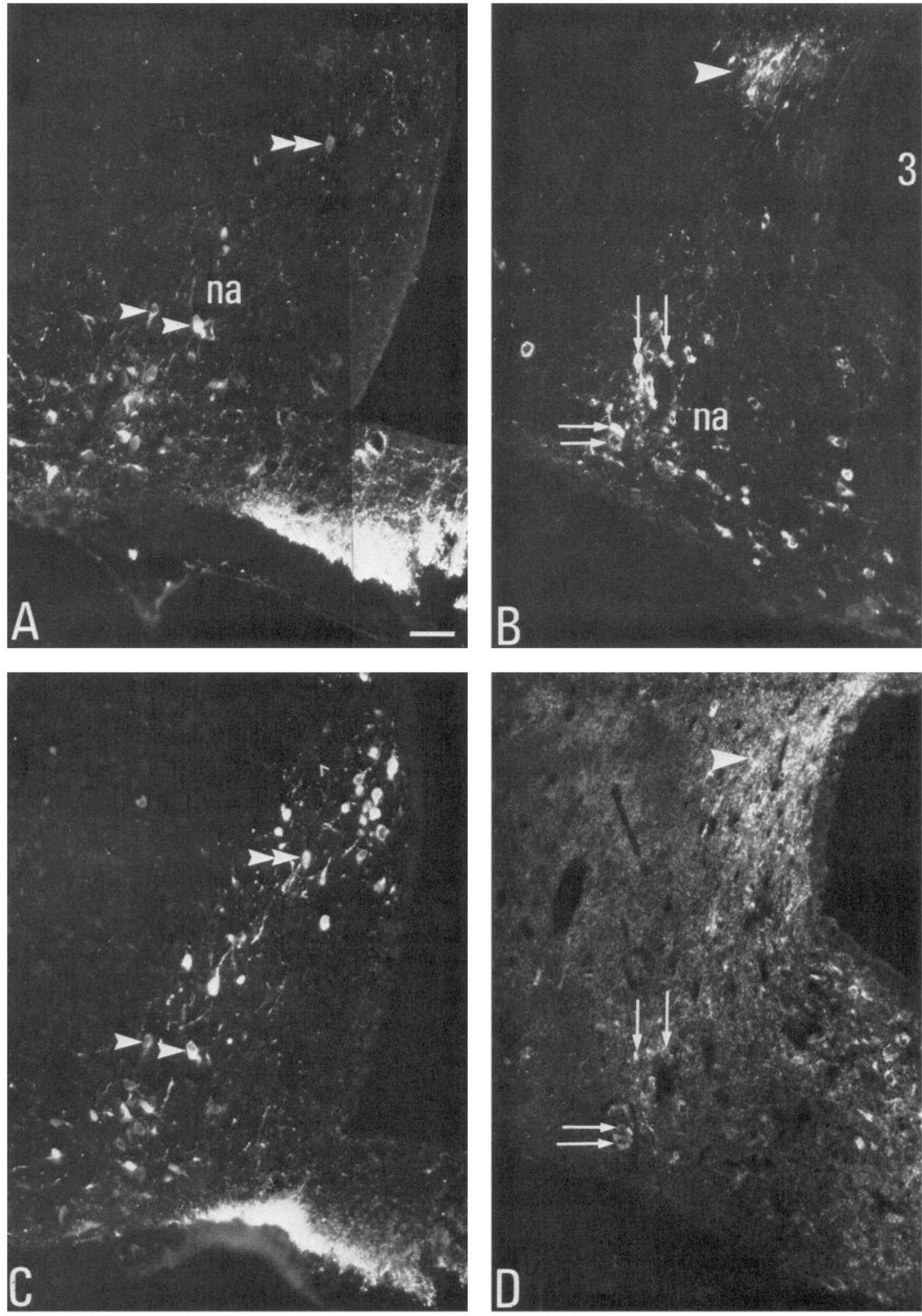

Figure 1. Immunofluorescence micrographs of sections through the arcuate nucleus $(n a)$ and median eminence after incubation with GAL $(A, B)$, TH $(C)$, and GAD $(D)$ antisera. $A$ and $C$, A large number of GAL-positive cell bodies are seen in the ventrolateral arcuate nucleus (arrowheads in $A$ ), and the majority of these are also TH positive (arrowheads in $C$ ), as shown on the same section processed according to the elution-restaining method. Only single GAL-/TH-IR double-staining cell bodies are seen in the dorsomedial parts (double arrowhead in $A$ and $C$ ), while the great majority of this subdivision contains TH single-labeled profiles. A very dense GAL-IR fiber plexus is seen in the lateral part of the external layer of the median eminence, partly overlapping with the TH-positive fibers. $B$ and $D$, Coexistence of GAL- and GAD-LI in cell bodies of the posterior arcuate nucleus is seen on adjacent sections. In the lateral part of the nucleus, the same cell profiles (arrows) can be identified in 
In the posterior parts of the arcuate nucleus, GAL- and THpositive cell bodies exhibited different distribution patterns: THIR cells were rare, whereas the number of GAL-positive cells increased. Thus, only a few cases of the coexistence of these 2 compounds were seen at posterior levels.

The apparent number of GAD-IR cell bodies in the arcuate nucleus was low under the present conditions of investigation. However, the number of fluorescent cell bodies increased at posterior levels. GAL-IR cell bodies in the posterior arcuate nucleus displayed a morphology and distribution pattern very similar to that of GAD-IR cells, and adjacent 5- $\mu$ m-thick sections, stained with GAL and GAD antisera, revealed that some of these GAL-positive cell bodies (Fig. $1 B$ ) also contained GADLI (Fig. 1D). In the median eminence and the infundibular stalk, dense networks of GAL-, TH-, and GAD-positive fibers were seen; these showed a partial overlap, especially in the lateral aspects of the external layer. Furthermore, double-labeling experiments revealed that GAL- and GAD-LI existed in the same terminals in the external layer of the median eminence (Fig. 2, $A, B)$.

A large proportion of the magnocellular and many parvocellular neurons in the paraventricular nucleus contained GALLI. Analysis of thin adjacent sections showed that the vast majority of these neurons also contained vasopressin-LI (Fig. 2, $C$, D).

The tuberal and the caudal magnocellular nuclei contained large, GAL-IR somata, while smaller ones were seen scattered medially and dorsally to the latter nucleus. Also, staining of adjacent sections revealed a similar distribution pattcrn of GALLI and GAD-LI; in fact, they were co-contained within the same neurons (Fig. 3, $A-D$ ). However, GAL-IR cell bodies were fewer compared to GAD-IR cell bodies ( $c f$. Fig. $3, A, B$ ).

Retrograde tracing from the occipital cortex revealed many Truc bluc-labcled ncurons in the caudal magnocellular nucleus, some of which also were GAL-IR (Fig. 3, E,F), indicating that some of the GAL-positive cell profiles within the caudal magnocellular nucleus project to the occipital cortex. Also, GALpositive fibers were detected throughout the cerebral cortex. Faintly labcled fine fibers were seen intermingled with sparse, heavily labeled coarse ones.

\section{Pons-medulla oblongata}

Most of the cell bodies of the noradrenergic locus coeruleus (A6 cell group; Fig. 4A) and the A4 (Fig. 4C) norepinephrine cells were strongly GAL-positive. Elution-restaining with the rabbit TH antiserum (Fig. 4, B, D) confirmed that all of these cells were also TH-positive. Small, GAL single-labeled cells were seen surrounding the locus coeruleus. Furthermore, double-labeling experiments revealed extensive pile-up of GAL- and THLI in the same swollen, cut fibers of the supracallosal striae (see Fig. $9, A, B$ ), as well as in varicose fibers in neocortical areas of control animals (Fig. 9, $C, D$ ).

GAL-positive somata were also seen in the ventrolateral medulla, essentially as 2 groups. One was located at the level of area postrema (Fig. $4 E$ ), and a second group extended along the basal surface of the medulla from the level of the rostral olive to the rostral levels of the facial nucleus (Fig. $4 G$ ). Although these cells intermingled with the epinephrine Cl cells, no evidence for coexistence was seen. Thus, elution-restaining and double-labeling experiments revealed that GAL- and TH-LI were completely segregated in these areas (Fig. $4, E-H$ ). A few GAL-positive cells have been observed in the ventrolateral cau- dal medulla oblongata dorsolateral to the lateral reticular nucleus; these cells were also TH-positive, thus placing them in the noradrenergic A1 cell group.

A very large number of small to medium somata were seen in the dorsal vagal complex (Figs. 5, 6). At levels rostral to area postrema, single cells were located in lateral parts of the medial subnucleus of the solitary tract nucleus (for nomenclature, see Kalia and Fuxe, 1985; Kalia and Sullivan, 1982). More caudally, greater numbers were seen in the medial subnucleus and in the commissural nucleus (Fig. 5A). A maximum of positive cell profiles was seen just caudal to the level of area postrema, where up to 50 small cell bodies were observed bilaterally, tightly clustered, mostly within the medial subnucleus (Fig. $5 C$ ). Single cells were also seen in the dorsal motor nucleus of the vagus nerve (Fig. $6, A, C$ ). In addition, small numbers of GAL-IR bipolar cells were detected at the medial border of the gracilis nucleus (Fig. 5A).

Double-labeling experiments using the monoclonal TH antibody revealed that the highest proportion of cells containing both GAL- and TH-LI was observed in the caudal aspects in the commissural nucleus of the dorsal vagal complex (Fig. 6, $A-D$ ). At the level of area postrema, only few cell bodies contained both peptide and enzyme (Fig. 5, $A-D$ ). Rostral to the area postrema, no instances of coexistence were encountered.

Most major nuclei containing 5-HT-positive somata also displayed GAL-IR cell bodies. A large proportion of the 5-HT-IR somata in the dorsal raphe nucleus (Fig. 7, $A, B$ ) as well as more ventrally located mesencephalic 5 -HT somata (Fig. $7, C, D$ ) cocontained GAL-IR. The raphe obscurus (Fig. $8 A$ ) and pallidus (Fig. 8C) nuclei contained GAL-IR neurons, and adjacent sections revealed that these neurons also contained 5-HT (Fig. 8, $A-D$ ). However, the raphe magnus nucleus appeared to lack GAL-IR.

Double staining also revealed the coexistence of GAL- and 5-HT-LI at the nerve fiber level in the hippocampal formation, in particular, concentrated inside the granule cell layer of the ventral dentate gyrus (Fig. 9, $E, F$ ).

It is of note that the mesencephalic GAL-IR somata were detected only with the GAL antiserum from Peninsula Laboratories. This was the only cell group studied in which the labeling with the R28310 and Peninsula GAL antisera differed.

\section{Controls}

None of the GAL-IR structures described above was observed after incubation with appropriate control sera. An exception was the medullary raphe nuclei, where preincubation of GAL antiserum R28310 with GAL peptide did not completely abolish fluorescence. However, when using the Peninsula GAL antiserum, adsorption with peptide entirely blocked fluorescence in these cells. No cross-reactivity (in the immunohistochemical model) was detected between the antisera used for double labeling.

\section{Discussion}

The present results demonstrate GAL-LI in neurons in the ventral hypothalamus and pons-medulla, with emphasis on comparison of the localization and distribution of TH-LI and GADLI, presumably markers for catecholamine and GABA neurons, respectively. 5-HT and vasopressin systems were also analyzed. Staining of adjacent sections, double-labeling experiments, and elution-restaining revealed several instances in which GAL-LI coexisted with TH-, GAD-, or 5-HT-LI, indicating the presence

$B$ and $D$ staining for GAL and GAD, respectively. In addition, a population of GAL- and GAD-positive cell profiles is seen in the tuberal magnocellular nucleus (large arrowheads in $B$ and $D$ ) dorsolateral to the third ventricle (3). Bar (in $A$ ), $50 \mu \mathrm{m}$. All micrographs have the same magnification. 

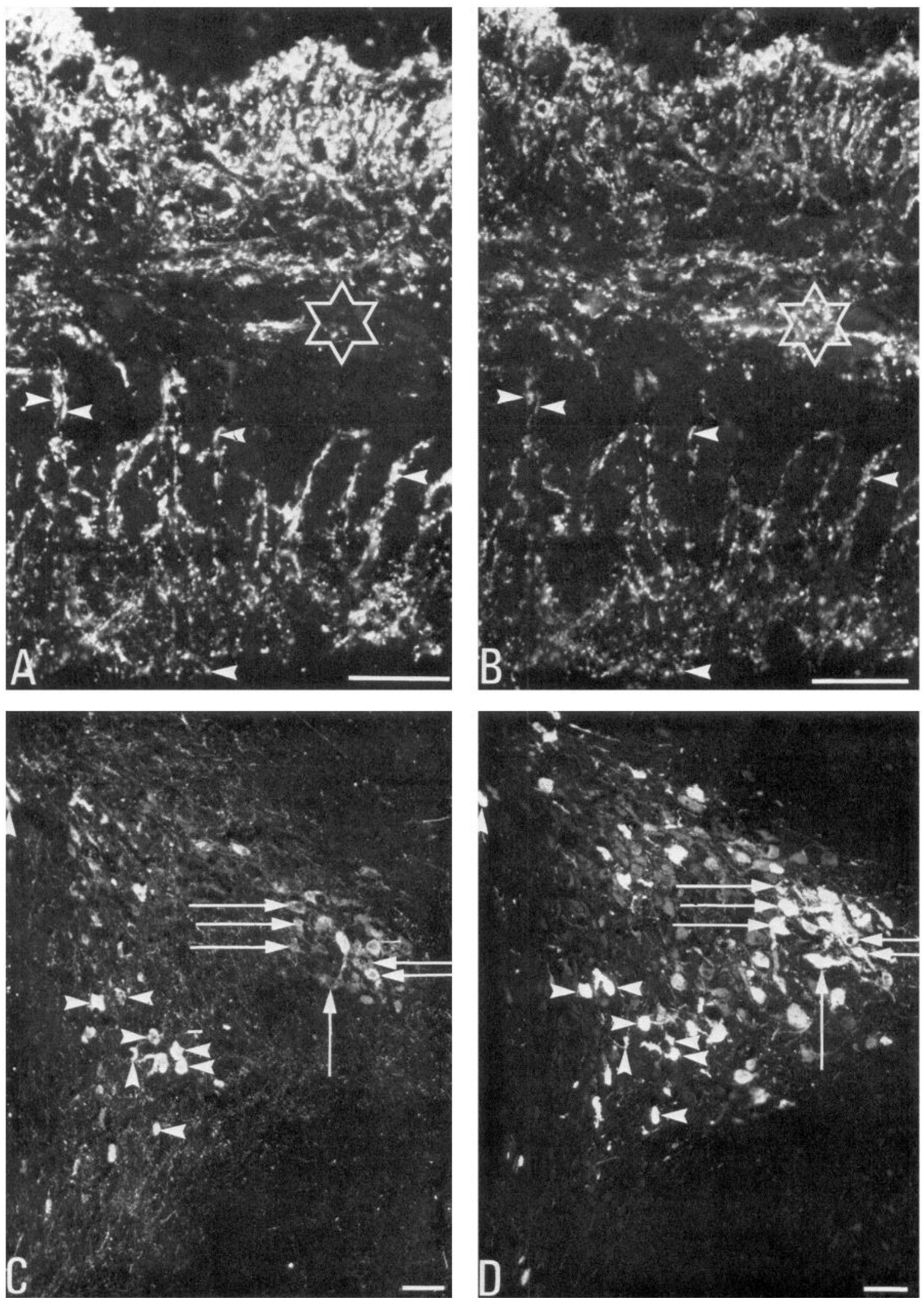

Figure 2. Immunofluorescence micrographs of the median eminence $(A, B)$ and paraventricular nucleus $(C, D)$ after incubation with GAL $(A, C)$, GAD $(B)$, and vasopressin $(D)$ antiserum. $A$ and $B$, Same section of the infundibular stalk has been processed for double staining and shows GAL in $A$ and GAD in $B$. The great majority of the fibers in the external layer co-contain GAL- and GAD-LI (arrowheads point to some examples). However, in the center of the stalk, GAD single-labeled nerves are seen (inside star). Single-labeled GAL-IR neuronal structures could not be detected with certainty in the median eminence or infundibular stalk but were seen, for example, in the dorsomedial nucleus, providing a control for cross-reactivity. $C$ and $D$, Adjacent sections through the posterior part of the paraventricular nucleus show several examples of presence of both GAL- and vasopressin-LI in the same cell profiles in the parvocellular (arrowheads) and magnocellular subnuclei (arrows). Bars, $50 \mu \mathrm{m}$. 

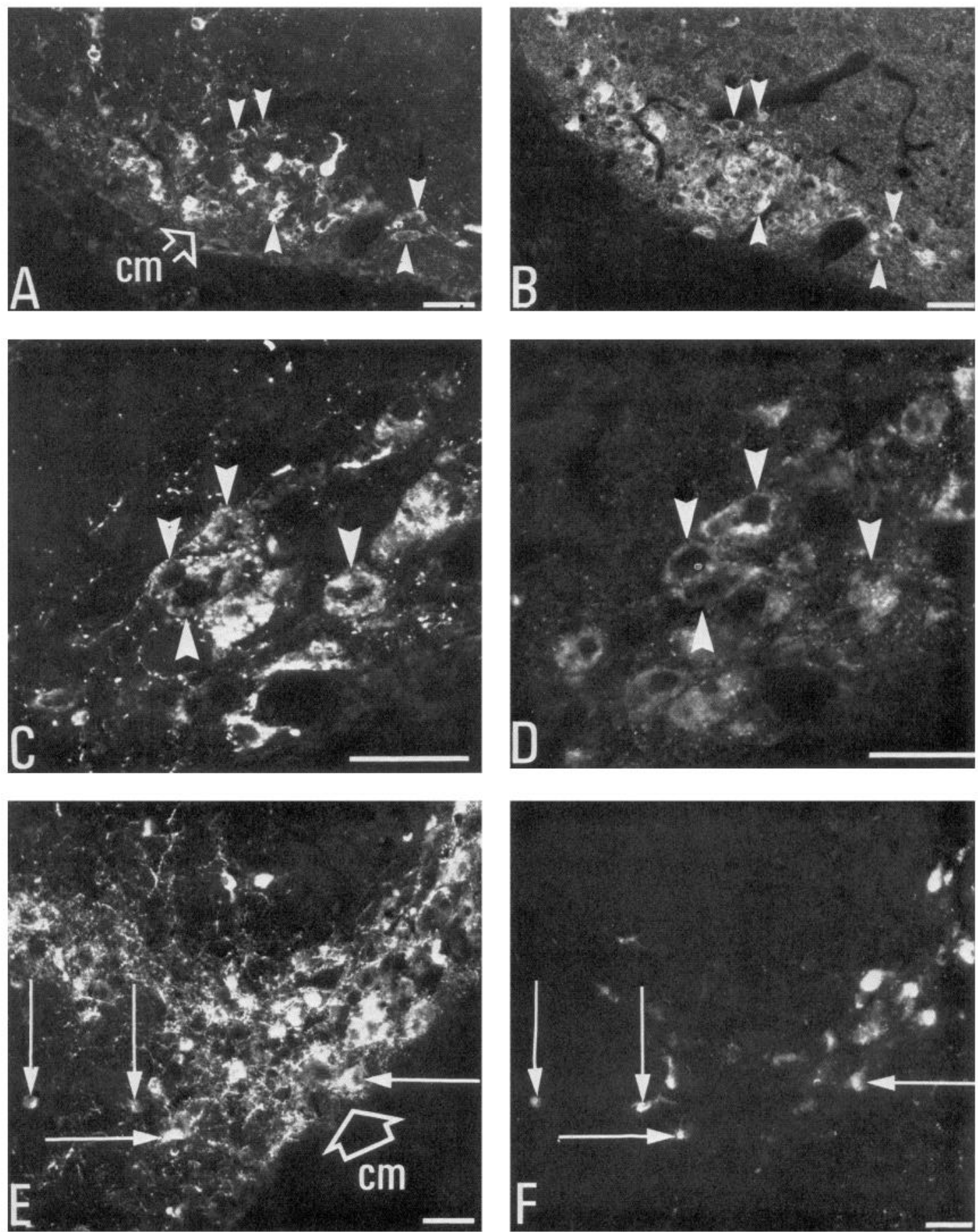

Figure 3. Immunofluorescence micrographs of the caudal magnocellular nucleus $(\mathrm{cm})$ after incubation with GAL $(A, C, E)$ and GAD $(B, D)$ antisera and fluorescence micrograph of True blue-labeled perikarya $(F) . A$ and $B$, Adjacent sections through the $\mathrm{cm}$ showing that many cell profiles contain both GAL- and GAD-LI (arrowheads). $C$ and $D$, High-power micrographs of the cm further visualizing the coexistence of GAL- and GAD$\mathrm{LI}$ in adjacent sections of this nucleus. $E$ and $F$, GAL-positive cell profiles (arrows in $E$ ) in the cm are seen to contain also the fluorescent tracer True blue $(F)$ after cortical injections. Bars, $50 \mu \mathrm{m}$.

of this peptide both in presumed dopamine neurons in the hypothalamus and norepinephrine and 5-HT neurons in the lower brain stem and mesencephalon, as well as in hypothalamic GABA neurons.

TH- and GAL-LI were found to coexist in the anterior and midportions of the arcuate nucleus, in the locus coeruleus, and in the caudal dorsal vagal complex, while overlapping but segregated populations were found in the ventrolateral medulla (mixed with the $\mathrm{Cl}$ epinephrine perikarya) and in parts of the dorsal vagal complex (mixed mainly with A2 norepinephrine cell bodies). GAD- and GAL-LI were co-contained in cell bodies of the posterior arcuate nucleus, as well as in fibers of the median eminence and in somata of the caudal magnocellular nucleus.

\section{Hypothalamus}

A wide array of transmitters and transmitter candidates is present in the arcuate nucleus. In particular, the TH-IR perikarya of the ventrolateral and dorsomedial cell groups of the anterior 

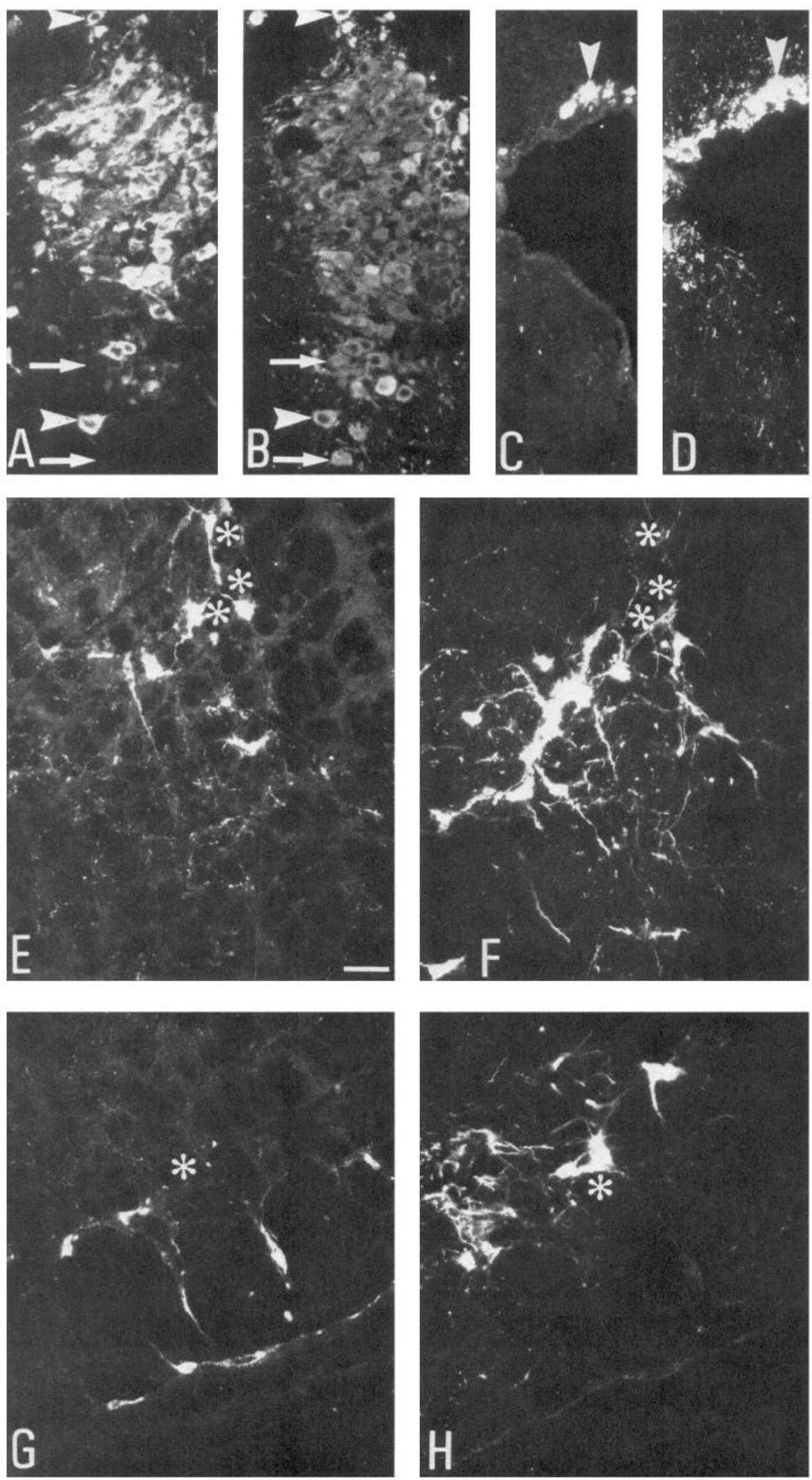

Figure 4. Immunofluorescence micrographs of the locus coeruleus $\mathrm{A} 6(A, B)$, A4 area $(C, D)$, ventrolateral, midcaudal $(E, F)$, and rostral $(G, H)$ medulla oblongata after incubation with $\operatorname{GAL}(A, C, E, G)$ and $\mathrm{TH}(B, D, F, H)$ antisera. $A$ and $B$, Locus coeruleus is seen with a large number of GAL-IR cell bodies $(A)$ that co-contain TH-LI (arrowheads). Several cases of TH single-labeled profiles are seen (arrows). $C$ and $D$, GAL- and TH-LI also coexist in the A4 norepinephrine group (arrowheads). $E$ and $F$, Incubation with GAL antiserum $(E)$ and restaining with TH antiserum $(F)$ reveal coextensive but segregated cell populations in the ventrolateral medulla oblongata. $G$ and $H$, At more rostral levels, a GAL-positive cell group is seen at the ventral margin of the brain $(G)$, but here also it is segregated from the TH-IR cells of the adrenergic Cl group shown in $H$. Asterisks in, respectively, $E$ and $F$, as well as $G$ and $H$, show the same unstained fiber bundles for orientation and comparison. Bar, $50 \mu$ m. All micrographs have the same magnification. 

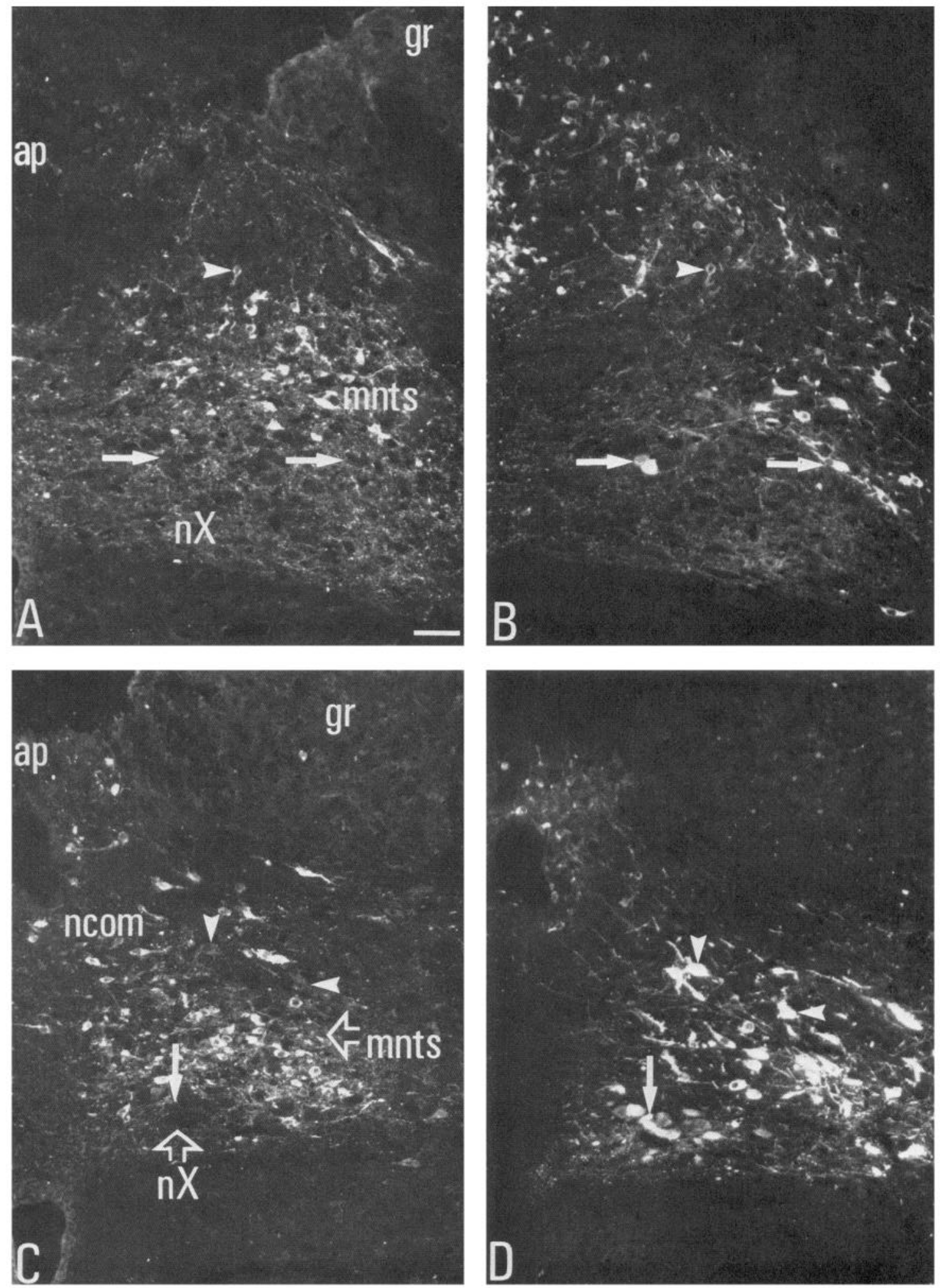

Figure 5. Immunofluorescence micrographs of sections through the dorsal vagal complex after double labeling with GAL $(A, C)$ and TH $(B, D)$ antisera. $A$ and $B$, Large number of small GAL-IR cell bodies are seen in the medial subnucleus of the nucleus of the solitary tract (mnts) at midlevels of area postrema ( $a p)$. A single GAL/TH double-staining cell body can be detected (arrowhead), but the vast majority of the TH-IR cell bodies do not contain GAL-LI (arrows) and vice versa. $C$ and $D$, Larger number of the small GAL single-labeled cells are seen in the mnts at the level of the caudal margin of area postrema, spreading dorsomedially into the commissural nucleus ( $n$ com). At this level, a small number of THpositive cells show a weak GAL-LI (arrowheads), while the majority of the TH-IR profiles remain GAL negative (arrows). A few small GALpositive/TH-negative cell bodies can be seen bordering the ap. $g r=$ gracilis nucleus; $n X=$ dorsal motor nucleus of the vagus nerve. Bar, $50 \mu \mathrm{m}$. All micrographs have the same magnification. 

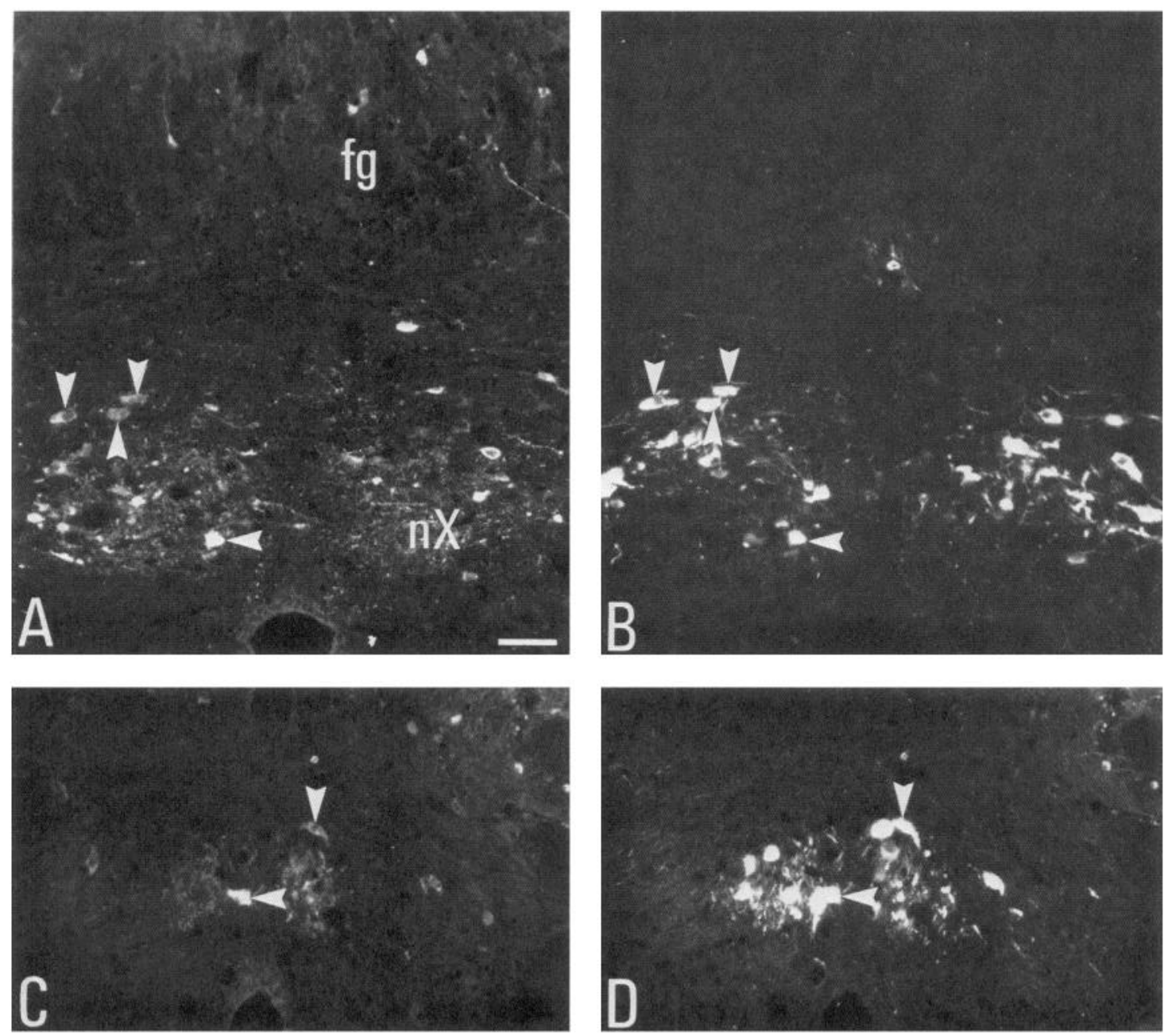

Figure 6. Immunofluorescence micrographs of sections through the dorsal vagal complex after double labeling with GAL $(A, C)$ and TH $(B, D)$ antisera. Caudal to area postrema several cell profiles co-contain GAL- and TH-LI (arrowheads). These are positioned both dorsal to (in the commissural nucleus) and within the dorsal motor nucleus of the vagus $(n X)$. A small population of GAL single-labeled cells is seen also at this level. $C$ and $D$, Single GAL- and TH-LI co-containing cells are detected dorsal to the central canal and also in the transition zone toward the spinal cord (arrowheads). $f g=$ gracilis fascicle. Bar (in $A$ ), $50 \mu \mathrm{m}$. All micrographs have the same magnification.

and midportions contain a variety of coexisting peptide immunoreactivities (see Everitt et al., 1986). These include, for example, growth hormone-releasing factor, though only in the ventrolateral group (Meister et al., 1985, 1986; Okamura et al., 1985); neurotensin-LI (Hökfelt et al., 1984a; Ibata et al., 1983); and GAL-LI, as shown here. The true nature of the transmitter (catecholamine?) in the ventrolateral TH-positive group in the arcuate nucleus is not fully resolved (see discussion in Everitt et al., 1986, and Meister et al., 1986). Thus, the labeling achieved with both our monoclonal and polyclonal TH antisera is consistently weaker in the ventrolateral than in the dorsomedial group, which has been the case also in other studies with the same or other antisera preparations (Chan-Palay et al., 1984; Everitt et al., 1986; Hökfelt et al., 1984c, d; Van den Pol et al., 1984). The possibility cannot be excluded that the TH-LI in cells in the ventrolateral group represents cross-reactivity with epitopes on proteins (enzymes) other than $\mathrm{TH}$, thus resulting in a weaker fluorescence. Studies are now in progress to analyze this question further, for example, by studying a possible coexistence of GAL (and other peptides) and TH in nerve terminals in the median eminence. In this respect it is important to point out that several other possible sources of GAL-LI in the median eminence exist in addition to those originating in the arcuate nucleus (Brownstein and Mezey, 1986; Melander et al., 1986a; Rökaeus et al., 1984; Skofitsch and Jacobowitz, 1985). Thus, GAL-IR cell bodies have been observed in other nuclei known to project to the median eminence (Lechan et al., 1982; Swanson and Sawchenko, 1983; Wiegand and Price, 1980), i.e., in the parvocellular paraventricular nucleus and anterior periventricular nucleus.

The present results also demonstrated that GAL-LI coexists with other markers in nerve endings in the median eminence. Thus, double-labeling experiments with GAD and GAL antisera revealed that a large proportion of the GAL-IR terminals in the median eminence are GAD positive. These GABA terminals could originate solely from the arcuate nucleus,

Figure 7. Immunofluorescence micrographs of sections through the dorsal raphe nucleus $(A, B)$, the posterior part of the interpeduncular nucleus $(C, D)$, and the dorsal vagal complex $(E, F)$ after double labeling with $\mathrm{GAL}(A, C, E)$ and 5-HT $(B, D, F)$ antisera. $A$ and $B$, Virtually all GAL-IR 

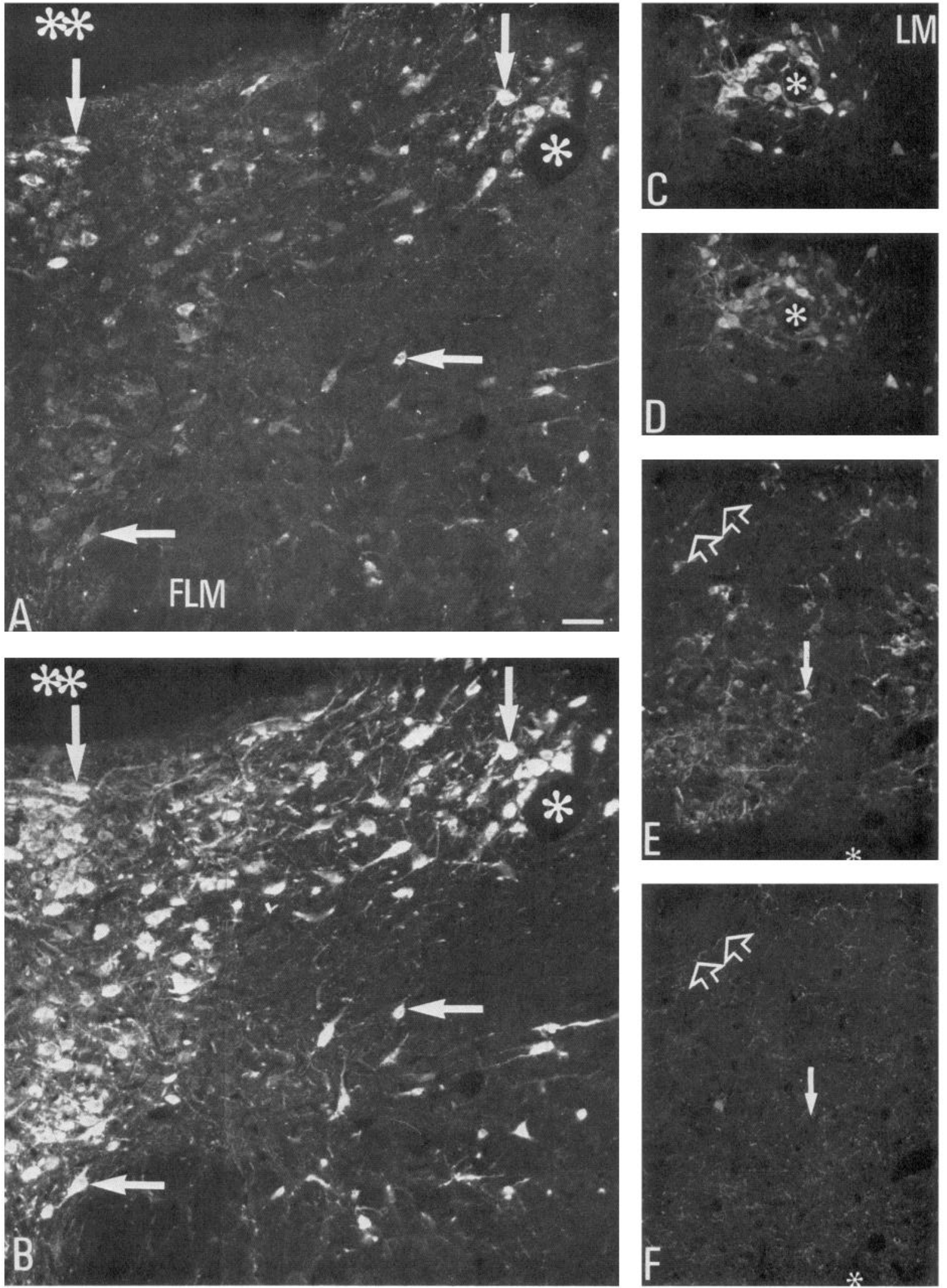

somata $(A)$ in the dorsal raphe nucleus co-contain 5-HT-LI $(B)$ and vice versa (arrows). The GAL-positive cell bodies vary considerably in intensity, with the more heavily labeled cells concentrated to the dorsal aspects of the nucleus. $C$ and $D$, Cluster of GAL- $(C)$ and 5-HT-positive $(D)$ somata forms a group, often surrounding a blood vessel (asterisk), in the lateral posterior part of the interpeduncular nucleus. $E$ and $F$, Segregation of GAL and 5-HT labeling in the dorsal vagal complex is shown. GAL-IR cell bodies are 5-HT negative (arrows) and 5-HT-IR fibers are GAL negative (open arrows). FLM, medial longitudinal fascicle; $L M$, medial lemniscus. Double asterisks in $A$ and $B$ depict the cerebral aqueduct; asterisks in $A-$ $D$ label blood vessels and in $E$ and $F$, the central canal. Bar (in $A$ ), $50 \mu \mathrm{m}$. All micrographs have the same magnification. 

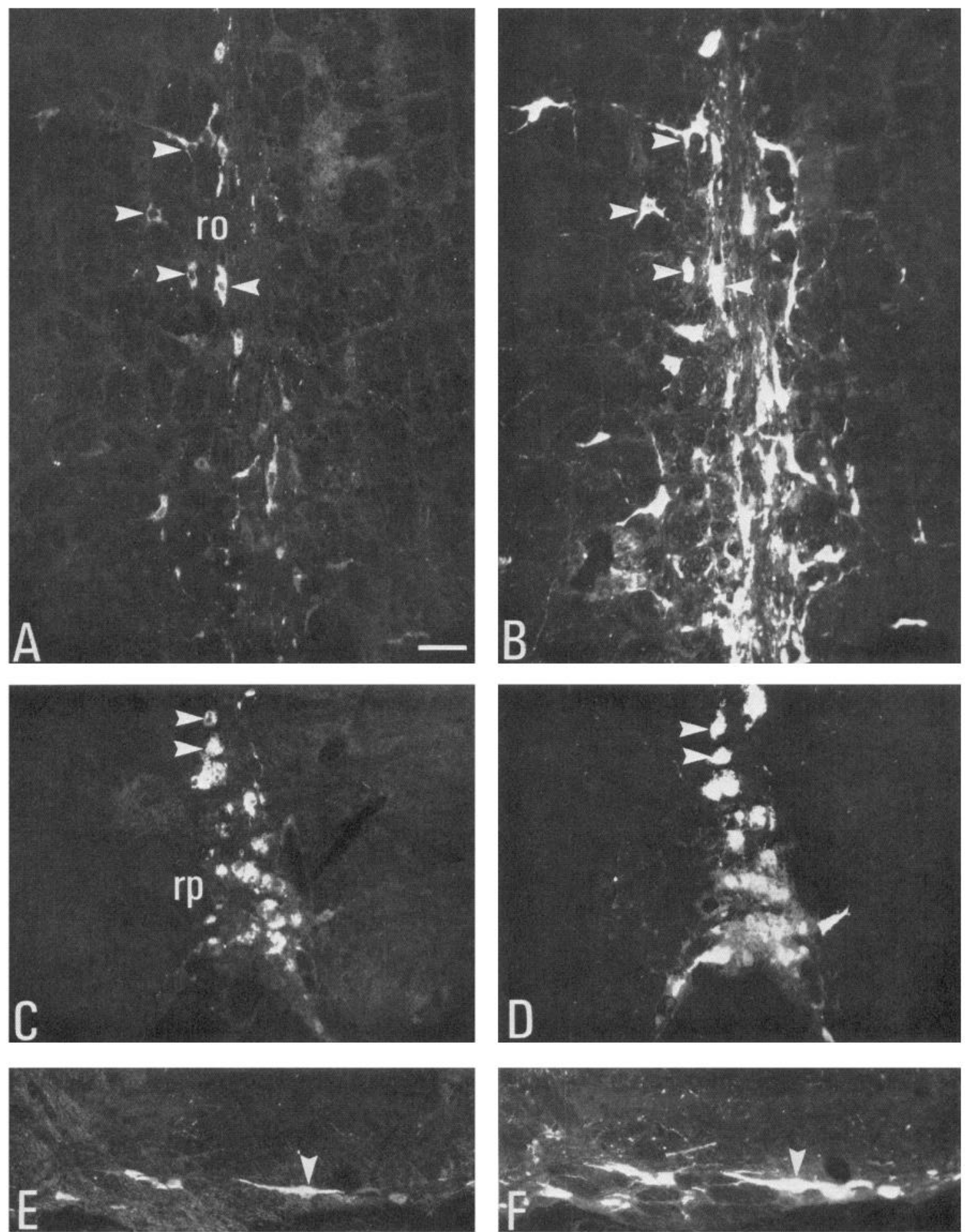

Figure 8. Immunofluorescence micrographs of sections through the medullary raphe nuclei after incubation with GAL $(A, C, E)$ and 5 -HT $(B$, $D, F)$ antisera. Adjacent sections stained for GAL and 5-HT revealed that some cell bodies of the raphe obscurus $(r o$ in $A$ and $B)$, as well as the raphe pallidus ( $r p$ in $C$ and $D$ ) co-contain GAL- and 5-HT-LI (arrowheads). $E$ and $F$, Double-labeled somata displaying GAL- $(E)$ and 5-HT-LI $(F)$ are seen lateral to the pyramidal tract (arrowheads). Bar, $50 \mu \mathrm{m}$. All micrographs have the same magnification.

since complete deafferentation of the medial-basal hypothalamis did not result in a decrease in GAD levels (Tappaz and Brownstein, 1977), and since arcuate lesions with monosodium glutamate caused a marked decrease in GAD in the median eminence (Walaas and Fonnum, 1978). This was further supported by demonstration of GAD-LI in cell bodies in the arcuate nucleus, in agreement with earlier studies (Everitt et al., 1984b, 1986; Mugnaini and Oertel, 1985; Tappat et al., 1983; Vincent et al., 1982), and their content of GAL-LI.

The neurons in the tuberal and caudal magnocellular nuclei (Bleier et al., 1979) appear to be another cell group characterized by a particularly large number of transmitters and peptide trans- 

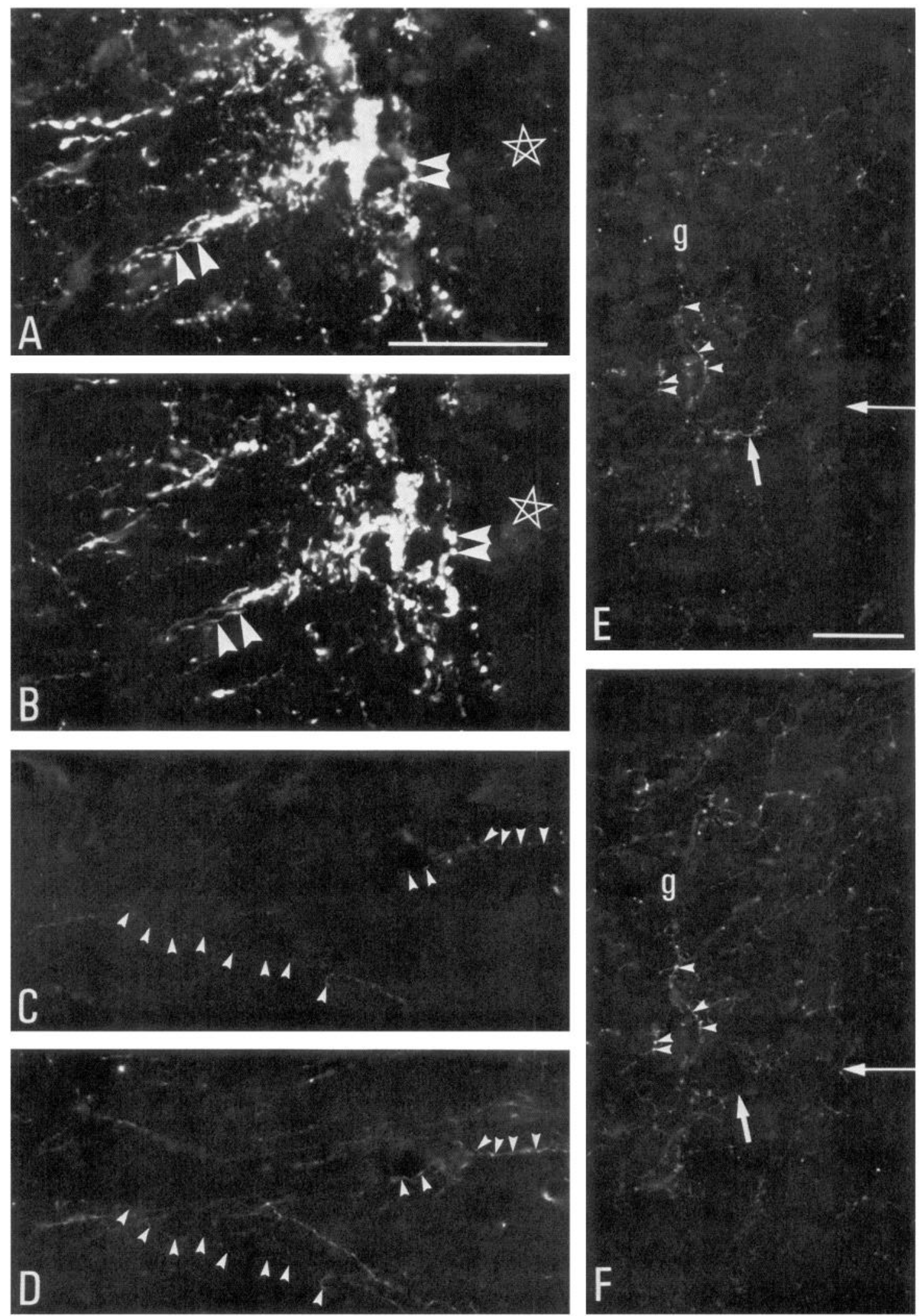

Figure 9. Immunofluorescence micrographs of sections through cingulate cortex $(A-D)$ and dentate gyrus $(E, F)$ after double labeling with $\mathrm{GAL}$ $(A, C)$ and TH $(B, D)$ antisera, as well as GAL $(E)$ and 5-HT $(F)$ antisera. $A$ and $B$, Pile-up of GAL- $(A)$ and TH-IR $(B)$ material is seen in the same swollen, lesioned nerve fibers (arrowheads) in the supracallosal striae, proximal to the knife-cut lesion (star). Virtually all labeled fibers contain both TH- and GAL-IR. $C$ and $D$, GAL- $(C)$ and TH-LI $(D)$ is seen co-contained within cortical fibers outlined by arrowheads. A large number of TH single-labeled fibers can be seen. $E$ and $F$, GAL $(E)$ and 5-HT $(F)$ immunoreactivities are seen in the same fibers and varicosities $(a r r o w h e a d s)$ in the dentate gyrus, intermingled within and just inside the granule cell layer. However, a large number of GAL single-labeled (thick arrows) and 5-HT single-labeled (thin arrows) fibers are present. Bars, $50 \mu \mathrm{m}$. $A-D$, and $E$ and $F$, respectively, have the same magnification. 
mitter candidates. Results indicate that these neurons are GABAergic, as shown here and previously (Mugnaini and Oertel, 1985; Vincent et al., 1982), and also contain the heptapeptide methionine-enkephalin-Arg ${ }^{6}-\mathrm{Phe}^{7}$ and substance P (Köhler et al., 1985), adenosine deaminase (Nagy et al., 1984), and histamine (Steinbusch and Mulders, 1984; Watanabe et al., 1984). These cell bodies have been shown to form direct cortical projections (Takeda et al., 1984; Vincent et al., 1983), a finding supported by combined retrograde tracing and GAL immunohistochemistry (present work). In fact, a population of coarse GAL-positive fibers is found in cortical areas; these fibers disappear after various types of lesions of subcortical afferents (Melander et al., 1986b).

\section{Pons-medulla oblongata}

The very extensive population of GAL-IR noradrenergic cell bodics in locus cocrulcus could represent another origin of some of the GAL-IR fibers observed in both neocortex and hippocampus. In fact, we were also able to show that GAL- and THLI coexist in a fine and faintly labeled subtype of cortical fibers, as well as in the supracallosal striae.

Numerous GAL-positive cell bodies were observed in the dorsal vagal complex, a region known to be rich in catecholamine and peptide neurons (see Leslie, 1985; Palkovits, 1985). Thus, norepinephrine, epinephrine, and possibly some dopamine neurons may exist here (Armstrong et al., 1982; Dahlström and Fuxe, 1964; Hökfelt et al., 1984c; Kalia et al., 1985). GAL-positive somata form a characteristic distribution pattern within the nucleus of the solitary tract. However, only a minor degree of coexistence with TH-LI could be established, with the highest numbers of cells in the medial subnucleus. Thus, a few of the norepinephrine cell bodies in the rostral A2 group cocontained GAL-LI, while a more pronounced coexistence was seen in the most caudal parts of the commissural nucleus and dorsal motor nucleus of the vagus. Whether these TH-positive cells are noradrenergic or lack dopamine- $\beta$-hydroxylase-and thus produce dopamine (Armstrong et al., 1982; Everitt et al., 1984a; Hökfelt et al., 1980a) or HL-Dopa (Jaeger et al., 1984)is at present unknown.

Present knowledge thus indicates that the majority of GAL neurons in the nucleus of the solitary tract lack catecholamine and, furthermore, probably give rise to local nerve terminal networks, since transections rostral to the dorsal vagal complex did not result in major disappearance of GAL-positive fibers in the dorsal vagal complex (H. S. Ceccatelli and T. Melander, unpublished observations). The medial subnucleus has been shown to receive afferent input from several peripheral sites through the vagus nerve and the GAL-IR/catecholamine neurons may, therefore, be involved in various autonomic functions processed in this region (for references, see Leslie, 1985). Preliminary experiments with intracisternal injections suggest that GAL has hypotensive effects in the nanomolar range in the $\alpha$-chloralose-anesthetized male rat (H. A. Härfstrand, unpublished observations).

The third major GAL-positive cell population in the lower brain stem was observed in the ventrolateral medulla oblongata, partly intermingled with the epinephrine neurons of the $\mathrm{Cl}$ group. However, in no case could coexistence of GAL-peptide and the epinephrine-synthesizing enzyme phenylethanolamine $N$-methyltransferase (PNMT)-LI be established. In contrast, GAL-positive cells located in the caudal ventrolateral medulla were always TH-positive and therefore belong to the Al norepinephrine cell group. However, it is interesting to note that several GAL-IR fiber systems in the mesencephalon and diencephalon closely resembled those containing the epinephrinesynthesizing enzyme PNMT-LI (Hökfelt et al., 1984c): for example, in the pcriventricular thalamic nucleus and in the periaqueductal central gray extending laterally dorsal to the su- perior cerebellar decussation. Thus, GAL-positive and PNMTIR neurons in the ventrolateral medulla oblongata may give rise to parallel ascending projections.

The existence of GAL-IR in the dorsal raphe nucleus was shown by Skofitsch and Jacobowitz (1985). The coexistence of GAL-LI with 5-HT shown here in the dorsal raphe nucleus is, to our knowledge, the first peptide co-immunoreactivity to be described within 5-HT neurons in this cell group, as well as in cortical 5-HT fibers. Thus, cotransmission may be important also for cortical 5-HT systems, long thought to be related to mood and depression and site of action of antidepressant drugs (see, e.g., Van Praag, 1978).

Finally, the GAL-positive neurons of the medullary raphe nuclei also contained 5-HT-like immunoreactivity. They may give rise to descending projections, since small numbers of GALIR fibers have been seen in, for example, the ventral horn of the spinal cord (Skofitsch and Jacobowitz, 1985), i.c., an arca known to receive projections from the medullary raphe (Brodal et al., 1960). The GAL immunofluorescence in the raphe cells was weaker than in most other areas and could not be seen as consistently as in other systems. Furthermore, as previously pointed out and discussed (Melander et al., 1986a), a small amount of fluorescence remained after incubation with GALpreadsorbed GAL antisera. This was, however, only true with the R28310 antiserum, whereas complete disappearance was seen with the commercially available Peninsula antiserum. It is possible that the rat has more than one peptide cross-reacting with our antiserum R28310 and/or that rat GAL is structurally different from pig GAL (the antibody was raised against the latter), as has been discussed elsewhere (Melander et al., 1985a, 1986a; Rökaeus et al., 1984).

It is of note that GAL-LI was also previously found in the direct cholinergic cortical projection from the septum-basal forebrain complex (Melander et al., 1985b). The existence of the same peptide in so many different cortical afferents, co-contained with such a wide variety of classical transmitters (GABA, $\mathrm{ACH}, 5-\mathrm{HT}$, and norepinephrine), might appear puzzling from a functional point of view. However, it must be kept in mind that our GAL antisera could visualize a family of peptides, as has previously been indicated (Rökaeus et al., 1984). A further puzzling issue is the fact that, although GAL-LI is present in many cortically projecting cell bodies, these somata seem to give rise to unexpectedly sparse cortical GAL-positive nerve terminals. The levels of GAL-LI may be too low to be detected with our technique, but several other explanations for this have been discussed previously (Melander et al., 1986b).

In conclusion, we have described the existence of GAL-IR with, among others, catecholamines, GABA, and 5-HT in the hypothalamus and pons-medulla of the rat; additionally, GALIR was found in parallel but segregated neuron populations in relation to catecholaminergic cell bodies and fibers. Some GALLI-containing brain areas, e.g., the arcuate nucleus and dorsal vagal complex, have been shown to contain particularly large numbers of other known transmitters and transmitter candidates and peptides; these compounds often coexist in various combinations. The peptide GAL represents a further addition to this set of compounds. The functional implications of our morphological findings remain to be examined, and physiological extensions of this work - in particular with reference to a possible GAL modulation of serotonergic, GABAergic and catecholaminergic transmission-are now essential.

\section{References}

Armstrong, D. M., C. A. Ross, V. P. Pickel, T. H. Joh, and D. J. Reis (1982) Distribution of dopamine, noradrenaline and adrenalinc-containing cell bodies in the rat medulla oblongata: Demonstration by the immunocytochemical localization of catecholamine biosynthetic enzymes. J. Comp. Neurol. 212: 173-187.

Bentivoglio, M., H. G. J. M. Kuypers, C. E. Catsman-Berrevoets, and 
O. Dann (1980) Two new fluorescent retrograde neuronal tracers which are transported over long distances. Neurosci. Lett. 18: 25-30. Bleier, R., P. Cohn, and I. R. Siggelkow (1979) A cytoarchitectonic atlas of the hypothalamus and hypothalamic third ventricle of the rat. In Anatomy of the Hypothalamus, Vol. 1, P. J. Morgane and J. Panksepp, eds., pp. 137-221, Dekker, New York.

Brodal, A., E. Taber, and F. Walberg (1960) The raphe nuclei of the brain stem in the cat-II. Efferent connections. J. Comp. Neurol. 114 239-282.

Brownstein, M. J., and E. Mezey (1986) Multiple chemical messengers in hypothalamic magnocellular neurons. In Progress in Brain $R e$ search, The Marcus Wallenberg Symposium on Coexistence of Neuronal Messengers: A New Principle of Chemical Transmission, Vol. 68, T. Hökfelt, K. Fuxe, and B. Pernow, eds., pp. 161-168, Elsevier, Amsterdam.

Chan-Palay, V., and S. L. Palay, eds. (1983) Coexistence of Neuroactive Substances, Wiley, New York.

Chan-Palay, V., L. Zaborszky, C. Köhler, M. Goldstein, and S. Palay (1984) Distribution of tyrosine hydroxylase-immunoreactive neurons in the hypothalamus of rats. J. Comp. Neurol. 227: 467-496.

Ch'ng, J. L. C., N. D. Christofides, P. Anand, S. J. Gibson, Y. S. Allen, H. C. Su, K. Tatemoto, J. F. B. Morrison, J. M. Polak, and S. R. Bloom (1985) Distribution of galanin immunoreactivity in the central nervous system and the responses of galanin-containing neuronal pathways to injury. Neuroscience I6: 343-354.

Coons, A. H. (1958) Fluorescent antibody methods. In General Cytochemical Methods, J. F. Danielli, ed., pp. 399-422, Academic, New York.

Cuello, A. C., ed. (1982) Co-transmission, MacMillan, London.

Dahlström, A. (1968) Fffect of colchicine on transport of amine storage granules in sympathetic nerves of rat. Eur. J. Pharmacol. 54: 111112.

Dahlström, $\Lambda$., and K. Fuxe (1964) Evidence for the existence of monoamine neurons in the central nervous system. I. Demonstration of monoamines in the cell bodies of brain stem neurons. Acta Physiol. Scand. [Suppl.] 232 62: 1-55.

Ekblad, E., R. Håkanson, F. Sundler, and C. Wahlestedt (1985a) Galanin: Neuromodulatory and direct contractile effects on smooth muscle preparations. Br. J. Pharmacol. 86: 241-246.

Ekblad, E., Å. Rökaeus, R. Håkanson, and S. Sundler (1985b) Galanin nerve fibers in the rat gut: Distribution, origin and projections. Neuroscience $16: 355-363$.

Elde, R. P. (1974) The production and characterization of anti-vasopressin antibodies and their use in the immunoenzyme histochemical localization of vasopressins in the hypothalamo-neurohypophysial neurosecretory system of several mammals. Ph.D. thesis, University of Minnesota, Minneapolis, MN.

Everitt, B. J., T. Hökfelt, L. Terenius, K. Tatemoto, V. Mutt, and M. Goldstein (1984a) Differential co-existence of neuropeptide Y (NPY)like immunoreactivity with catecholamines in the central ncrvous system of the rat. Neuroscience 11: 443-462.

Everitt, B. J., T. Hökfelt, J.-Y. Wu, and M. Goldstein (1984b) Coexistence of tyrosine hydroxylase-like and gamma-aminobutyric acidlike immunoreactivities in neurons of the arcuate nucleus. Neuroendocrinology 39: 189-191.

Everitt, B. J., B. Meister, T. Hökfelt, T. Melander, L. Terenius, Å. Rökaeus, E. Theodorsson-Norheim, G. Dockray, J. Edwardson, C. Cuello, R. Elde, M. Goldstein, H. Hemmings, C. Ouimet, I. Walaas, P. Greengard, W. Vale, E. Weber, and J.-Y. Wu (1986) The hypothalamic arcuate nucleus-median eminence complex: Immunohistochemistry of transmitters, peptides and DARPP-32 with special reference to coexistence in dopamine neurons. Brain Res. Rev. 11: 97-155.

Hartman, B. K., D. Zide, and S. Udenfriend (1972) The use of dopamine $\beta$-hydroxylase as a marker for noradrenergic pathways of the central nervous system in the rat. Proc. Natl. Acad. Sci. USA 69: 2722-2726.

Hökfelt, T., and A. Dahlström (1971) Effects of two mitosis inhibitors (colchicine and vinblastine) on the distribution and axonal transport of noradrenaline storage particles, studied by fluorescence and electron microscopy. Z. Zellforsch. 119: 460-482.

Hökfelt, T., K. Fuxe, M. Goldstein, and O. Johansson (1974) Immunohistochemical evidence for the existence of adrenaline neurons in the rat brain. Brain Res. 66: 235-251.

Hökfelt, T., M. Goldstein, K. Fuxe, O. Johansson, A. Verhofstad, H. Steinbusch, B. Penke, and J. Vargas (1980a) Histochemical iden- tification of adrenaline containing cells with special reference to neurons. In Central Adrenaline Neurons. Basic Aspects and Their Role in Cardiovascular Functions, K. Fuxe, M. Goldstein, B. Hökfelt, and T. Hökfelt, eds., pp. 19-47, Pergamon, New York.

Hökfelt, T., O. Johansson, $\AA$. Ljungdahl, J. M. Lundberg, and M. Schultzberg (1980b) Peptidergic neurons. Nature 284: 515-521.

Hökfelt, T., B. J. Everitt, E. Theodorsson-Norheim, and M. Goldstein (1984a) Occurrence of neurotensin-like immunoreactivity in subpopulations of hypothalamic, mesencephalic and medullary catecholamine neurons. J. Comp. Neurol. 222: 543-549.

Hökfelt, T., O. Johansson, and M. Goldstein (1984b) Chemical anatomy of the brain. Science 225: 1326-1334.

Hökfelt, T., O. Johansson, and M. Goldstein (1984c) Central catecholamine neurons as revealed by immunohistochemistry with special reference to adrenaline neurons. In Handbook of Chemical Neuroanatomy. Vol. 2: Classical Transmitters in the CNS. Part 1, A. Björklund and T. Hökfelt, eds., pp. 157-277, Elsevier, Amsterdam.

Hökfelt, T., R. Mårtensson, A. Björklund, S. Kleinau, and M. Goldstein (1984d) Distributional maps of tyrosine-hydroxylase-immunoreactive neurons in the rat brain. In Handbook of Chemical Neuroanatomy, Vol. 2: Classical Transmitters in the CNS, Part 1, S. Björklund and T. IIökfelt, eds., pp. 277-379, Elsevier, Amsterdam.

Ibata, Y., K. Fukui, H. Okamura, T. Kawakami, M. Tanaka, H. L. Obata, T. Tsuto, H. Terubayashi, C. Yanaihara, and N. Yanaihara (1983) Coexistence of dopamine and neurotensin in hypothalamic arcuate and periventricular neurons. Brain Res. 269: 177-179.

Jaeger, C. B., D. A. Ruggiero, V. R. Albert, D. H. Park, T. H. Joh, and D. J. Reis (1984) Aromatic L-amino acid decarboxylase in the rat brain: Immunocytochemical localization in neurons of the brain stem. Neuroscience 11: 691-713.

Johnson, D. G., and G. M. de C. Nogueira Araujo (1981) A simple method of reducing the fading of immunofluorescence during microscopy. J. Immunol. Methods 43: 349.

Kalia, M., and K. Fuxe (1985) Rat medulla oblongata. I. Cytoarchitectonic considerations. J. Comp. Neurol. 233: 285-307.

Kalia, M., and J. M. Sullivan (1982) Brainstem projections of sensory and motor components of the vagus nerve in the rat. J. Comp. Neurol. 211: 248-264.

Kalia, M., K. Fuxe, and M. Goldstein (1985) Rat medulla oblongata. II. Dopaminergic, noradrenergic (Al and A2) and adrenergic neurons, nerve fibers, and presumptive terminal processes. J. Comp. Neurol. 233: 308-332.

Köhler, C., L. W. Swanson, L. Haglund, and J.-Y. Wu (1985) The cytoarchitecture, histochemistry and projections of the tuberomammillary nucleus in the rat. Neuroscience 16: 85-110.

Kreutzberg, G. (1969) Neuronal dynamics and axonal flow-IV. Blockage of intra axonal enzyme transport. Proc. Natl. Acad. Sci. USA $62: 722-728$.

Lechan, R. M., J. L. Nestler, and S. Jacobson (1982) The tuberoinfundibular system of the rat as demonstrated by immunohistochemical localisation of retrogradely transported wheat germ agglutinin (WGA) from the median eminence. Brain Res. 245: 1-15.

Leslie, R. A. (1985) Neuroactive substances in the dorsal vagal complex of the medulla oblongata: Nucleus of the tractus solitarius, area postrema, and dorsal motor nucleus of the vagus. Neurochem. Int. 7: $191-211$.

Lundberg, J. M., B. Hedlund, A. Änggård, J. Fahrenkrug, T. Hökfelt, K. Tatemoto, and T. Bartfai (1982) Costorage of peptides and classical transmitters in neurons. In Systemic Role of Regulatory Peptides, S. R. Bloom, J. M. Polak, and E. Lindenlaub, eds., pp. 93-119, Schattauer, Stuttgart.

Markey, K. A., S. Kondo, L. Shenkman, and M. Goldstein (1980) Purification and characterization of tyrosine hydroxylase from a clonal phaeochromocytoma cell line. Mol. Pharmacol. 17: 79-85.

McDonald, T. J., J. Dupre, K. Tatemoto, G. R. Greenberg, J. Radziuk, and V. Mutt (1985) Galanin inhibits insulin secretion and induces hyperglycemia in dogs. Diabetes 34: 192-196.

Meister, B., T. Hökfelt, W. W. Vale, and M. Goldstein (1985) Growth hormone-releasing factor (GRF) and dopamine coexist in hypothalamic arcuate neurons. Acta Physiol. Scand. 124: 133-136.

Meister, B., T. Hökfelt, W. W. Vale, P. E. Sawchenko, L. W. Swanson, and M. Goldstein (1986) Coexistence of tyrosine hydroxylase and growth hormone-releasing factor in a subpopulation of tuberoinfundibular neurons of the rat. Neuroendocrinology 42: 237-247.

Melander, T., T. Hökfelt, Å. Rökaeus, K. Tatemoto, and V. Mutt (1984) 
Galanin immunoreactive neurons in the central and peripheral nervous system. Ann. Soc. Neurosc. Meet. 208: 8.

Melander, T., T. Hökfelt, Å. Rökaeus, J. Fahrenkrug, K. Tatemoto, and V. Mutt (1985a) Distribution of galanin-like immunoreactivity in the gastro-intestinal tract of several mammalian species. Cell Tissue Res. 239: 253-270.

Melander, T., W. A. Staines, T. Hökfelt, $\AA$. Rökaeus, F. Eckenstein, P. M. Salvaterra, and B. H. Weiner (1985b) Galanin-like immunoreactivity in cholinergic neurons of the septum-basal forebrain complex projecting to the hippocampus of the rat. Brain Res. 360: 130138.

Melander, T., T. Hökfelt, and $\AA$. Rökaeus (1986a) Distribution of galanin-like immunoreactivity in the rat central nervous system. J. Comp. Neurol. 248: 475-517.

Melander, T., W. A. Staines, and $\AA$. Rökaeus (1986b) Galanin-like immunoreactivity in hippocampal afferents with spccial reference to cholinergic and noradrenergic inputs. Neuroscience (in press).

Mugnaini, E., and W. H. Oertel (1985) An atlas of the distribution of GABAergic neurons and terminals in the rat CNS as revealed by GAD immunohistochemistry. In Handbook of Chemical Neuroanatomy, Vol. 4: GABA and Neuropeptides in the CNS, Part 1, A. Björklund and T. Hökfelt, eds., pp. 456-608. Elsevier, Amsterdam.

Nagy, J. I., L. A. LaBella, M. Buss, and P. E. Daddona (1984) Immunohistochemistry of adenosine deaminase: Implications for adenosine neurotransmission. Science 224: 166-168.

Nairn, R. C. (1969) Fluorescent Protein Tracing, Livingstone, Edinburgh.

Oertel, W. H., D. E. Schmechel, M. L. Tappaz, and I. J. Kopin (1981) Production of a specific antiserum to rat brain glutamic acid decarboxylase by injection of an antigen-antibody complex. Neuroscience 6: 2689-2700.

Okamura, H., S. Murakami, K. Chihara, I. Nagatsu, and Y. Ibata (1985) Coexistence of growth hormone releasing factor-like and tyrosine hydroxylase-like immunoreactivities in neurons of the rat arcuate nucleus. Neuroendocrinology 41:177-179.

Ottlecz, A., W. K. Samson, and S. M. McCann (1985) Hypothalamic site of action of galanin to stimulate growth hormone release. Endocrine Soc. Abstr. 480.

Palkovits, M. (1985) Distribution of neuroactive substances in the dorsal vagal complex of the medulla oblongata. Neurochem. Int. 7: 213-219.

Platt, J. L., and A. F. Michael (1983) Retardation of fading and enhancement of intensity of immunofluorescence by p-phenylenediamine. J. Histochem. Cytochem. 31: 840-842.

Rökaeus, $\dot{\AA}$., T. Melander, T. Hökfelt, J. M. Lundberg, K. Tatemoto, M. Carlquist, and V. Mutt (1984) A galanin-like peptide in the central nervous system and intestine of the rat. Neurosci. Lelt. 47: $161-166$.

Semenenko, F. M., A. C. Cuello, M. Goldstein, K. Y. Lee, and E. Sidebottom (1986) A monoclonal antibody against tyrosine hydroxylase: Application in light and electron microscopy. J. Histochem. Cytochem. 34: 817-821.

Skofitsch, G., and D. M. Jacobowitz (1985) Immunohistochemical mapping of galanin-like neurons in the rat central nervous system. Peptides 6: 509-546.

Steinbusch, H. W. M., and A. H. Mulders (1984) Immunohistochemical localization of histamine in neurons and mast cells in the rat brain. In Handbook of Chemical Neuroanatomy, Vol. 3: Classical Transmitters and Transmitter Receptions in the CNS, Part II, A. Björklund, T. Hökfelt, and M. Kuhar, eds., pp. 126-140, Elsevier, Amsterdam.
Steinbusch, H. W. M., A. A. J. Verhofstad, and H. W. J. Joosten (1978) Localization of scrotonin in the central nervous system by immunohistochemistry: Description of a specific and sensitive technique and some applications. Neuroscience 3: 811-819.

Swanson, L. W., and P. E. Sawchenko (1983) Hypothalamic integration: Organization of the paraventricular and supraoptic nuclei. Annu. Rev. Neurosci. 6: 275-325.

Takeda, N., S. Inagaki, Y. Taguchi, M. Tohyama, T. Watanabe, and H. Wada (1984) Origin of histamine containing fibers in the cerebral cortex of rats studied by immunohistochemistry with histidine decarboxylase as a marker and transection. Brain Res. 323: 55-63.

Tappaz, M. L., and M. J. Brownstein (1977) Origin of glutamatedecarboxylase (GAD)-containing cells in discrete hypothalamic nuclei. Brain Res. 132: 95-106.

Tappaz, M. L., M. Wassef, W. H. Oertel, L. Paut, and J. F. Pujol (1983) Light- and electron-microscopic immunocytochemistry of glutamic acid decarboxylase (GAD) in the basal hypothalamus: morphological evidence for neuroendocrine gamma-aminobutyrate (GABA). Neuroscience 9: $271-287$.

Tatemoto, K., А. Rökaeus, H. Jörnvall, T. J. McDonald, and V. Mutt (1983) Galanin-A novel biologically active peptide from porcine intestine. FEBS Lett. 164: 124-128.

Tramu, G., A. Pillez, and J. Leonardelli (1978) An efficient method of antibody elution for the successive or simultaneous location of two antigens by immunocytochemistry. J. Histochem. Cytochem. 26: 322324.

Van den Pol, A. N., R. S. Herbst, and J. F. Powell (1984) Tyrosine hydroxylase-immunoreactive neurons of the hypothalamus: A light and electron microscopic study. Neuroscience 13: 1117-1156.

Van Praag, H. M. (1978) Amine hypothesis of affective disorders. In Handbook of Psychopharmacology, Vol. 13: Biology of Mood and Antianxiety Drugs, L. L. Iversen, S. D. Iversen, and S. H. Snyder, eds., pp. 187-297, Plenum, New York.

Verhofstad, A. A. J., H. V. M. Steinbusch, H. W. J. Joosten, B. Penke, J. Varga, and M. Goldstein (1983) Immunocytochemical localization of noradrenaline, adrenaline and serotonin. In Immunocytochemistry; Practical Applications in Pathology and Biology, J. M. Polak and S. Van Norden, eds., pp. 143-168, Wright, Bristol, U.K.

Vincent, S. R., T. Hökfelt, and J.-Y. Wu (1982) GABA neuron system in hypothalamus and pituitary gland: Immunohistochemical demonstration using antibodies against glutamate decarboxylase. Neuroendocrinology $34: 117-125$.

Vincent, S. R., T. Hökfelt, L. R. Skirboll, and J.-Y. Wu (1983) Hypothalamic $\gamma$-aminobutyric acid neurons project to the neocortex. Science 220: 1309-1311.

Walaas, S. I., and F. Fonnum (1978) The effect of parenteral glutamate treatment on the localization of neurotransmitters in the mediobasal hypothalamus. Brain Res. 153: 549-562.

Watanabe, T., Y. Taguchi, S. Shiosaka, J. Tanaka, H. Kubota, Y. Terano, M. Tohyama, and H. Wada (1984) Distribution of the histaminergic neuron system in the central nervous system of rats: A fluorescent immunohistochemical analysis with histidine decarboxylase as a marker. Brain Res. 295: 13-25.

Wiegand, S. J., and J. L. Price (1980) Cells of origin of the afferent fibres to the median eminence in the rat. J. Comp. Neurol. 192: 119.

Zamboni, L., and C. de Martino (1967) Buffered picric acid formaldehyde: A new rapid fixative for electron microscopy. J. Cell Biol. 148A: 35 . 